\title{
EL MODELO EXTRACTIVISTA Y LOS PELIGROS PARA LA SOBERANÍA ALIMENTARIA EN EL CASO ECUATORIANO
}

\author{
Enith Flores Chamba*
}

Resumen. Las políticas extractivistas basadas en la implementación de proyectos mineros, petroleros, agronegocios traen consigo el desplazamiento de pueblos y comunidades de sus territorios, el acaparamiento de tierras, la disputa por el uso, tenencia y control de recursos como el agua, la tierra, las semillas, el abandono y desinterés por preservar y promover la agricultura familiar campesina. Todos estos son factores que evidencian una clara violación a la soberanía alimentaria al no asegurar desde el Estado el acceso a los recursos fundamentales para una alimentación cultural y socialmente adecuada. En América Latina, Ecuador es uno de los países que ha firmado y ratificado los convenios internacionales vinculados a Derechos Económicos, Sociales, Culturales y Derecho a la Alimentación (DESCA). Sin embargo, las políticas implementadas en la última década entran en contradicción con el PIDESC y la Constitución ecuatoriana (Registro Oficial, 2008), que garantiza los DESCA a través de lo que se denomina Derechos del Buen Vivir o Sumak Kawsay. A lo largo de este trabajo se analiza la importancia de la soberanía alimentaria en el Ecuador y sus riesgos con las políticas extractivistas implementadas por los últimos gobiernos.

Palabras Clave: Extractivismo; Soberanía alimentaria; Ecuador.

\footnotetext{
* Maestranda de Economía Social en la Universidad Nacional de General Sarmiento (UNGS), Argentina.
}

Contacto: enithlisa@yahoo.es 


\title{
THE EXTRACTIVIST MODEL AND THE RISK FOR FOOD SOVEREIGNTY IN THE ECUADORIAN CASE
}

\begin{abstract}
As a result of extractivist policies associated with the implementation of mining and petroleum projects and agribusiness, there has been the removal and displacement of many communities, often indigenous from their territories. There are major disputes as a result of this land grabbing, with respect to the use, tenancy and control of natural resources, such as water, land, seeds, and often the resulting abandonment of lack of support for preserving and promoting peasant family agriculture. All these factors which provide evidence of a clear violation of food sovereignty, since the State is not insuring access to fundamental resources for to insure alimentation and nutrition which is both culturally and socially appropriate. Within Latin America, Ecuador is one of the countries that has signed and ratified the international agreements associated with ESCR (Economic, Social and Cultural Rights) and the Right to Food. However, the policies implemented during the last decade are in contradiction with ICESCR and the Ecuadorian Constitution (Official Register, 2008), which guarantees the ESCR through that which is referred to as the rights of Buen Vivir or Sumak Kawsay. Throughout this article the importance of food sovereignty is analyzed in the case of Ecuador and the risks which threaten this given the extractivist policies implemented by recent governments.
\end{abstract}

Keywords: Extractivism; Food Sovereignty; Ecuador.

Original recibido el 16/01/2018

Aceptado para su publicación el 11/11/2018 


\section{Introducción}

El reconocimiento de la interculturalidad, el respeto por los saberes ancestrales, la acción colectiva de los movimientos sociales, entre otros factores, han llevado a que varios países de América Latina incluyan en sus legislaciones otras visiones de cómo construir la sociedad, formas de vivir que ponen en cuestionamiento al capitalismo, al patriarcado y al colonialismo.

Este trabajo presenta un análisis sobre cómo a pesar de contar con tratados internacionales y legislaciones que promueven el respeto, protección y garantía de los Derechos Económicos, Sociales, Culturales y Ambientales (DESCA), la implementación de modelos económicos basados en el extractivismo hace que dichos derechos se pongan en riesgo, o sean violados en su mayoría.

Las políticas extractivistas basadas en la implementación de proyectos mineros, petroleros, monocultivos para los agronegocios traen consigo el desplazamiento de pueblos y comunidades de sus territorios, el acaparamiento de tierras, la disputa por el uso, tenencia y control de recursos como el agua, la tierra, las semillas, el abandono y desinterés por preservar la agricultura familiar campesina. Todos estos son factores que denotan una clara violación a la soberanía alimentaria al no asegurar desde el Estado el acceso a los recursos básicos para una alimentación cultural y socialmente adecuada.

En América Latina, Ecuador es uno de los países que ha firmado y ratificado el Pacto Internacional de Derechos Económicos, Sociales y Culturales (PIDESC) (Committee on Economic, Social And Cultural Rights, 1966), así como las Directrices Voluntarias del Derecho a la Alimentación (Organización de las Naciones Unidas para la Alimentación y la Agricultura [FAO], 2005). Sin embargo, las políticas implementadas en la última década entran en contradicción con el PIDESC y la Constitución ecuatoriana (Registro Oficial, 2008), que garantiza los DESCA a través de lo que se denomina Derechos del Buen Vivir o Sumak Kawsay.

A lo largo de este trabajo se analiza la importancia de la soberanía alimentaria en el Ecuador y sus riesgos con las políticas extractivistas implementadas por los últimos gobiernos. En la sección 2 se desarrolla la relación entre los Derechos Económicos, Sociales, Culturales, Ambientales y el Buen Vivir, desde un análisis más conceptual y epistémico del Buen Vivir y Sumak Kawsay. En la sección 3 se concreta cómo la soberanía alimentaria es parte del Buen Vivir, concebida históricamente como una propuesta desde los pueblos originarios, así como desde las mujeres y su relación con el territorio. En la sección 4 se analiza los cambios que se dan a partir del ascenso del gobierno de Correa en torno al modelo de desarrollo implementado en el país y su continuidad con el gobierno de Moreno. En la sección 5 se detalla cuál es la situación de la soberanía alimentaria en Ecuador, tanto en cuestiones jurídicas como en la práctica. En la sección 6 se desarrollan las incompatibilidades constitucionales que se presentan entre la construcción de la soberanía alimentaria y las políticas extractivistas en desarrollo. En la sección 7 se retoma la relación de las mujeres en torno a la soberanía alimentaria y sus prácticas frente a las crisis económicas. Para terminar en la sección 8 se plantean conclusiones básicas de la situación de la soberanía alimentaria en relación a las políticas extractivas que se 
vienen implementando en Ecuador.

\section{La importancia de los DESCA en la construcción del Buen Vivir ${ }^{1}$}

El ejercicio pleno de los derechos humanos requiere de instrumentos que permitan en la práctica su real concreción. Dichos instrumentos necesariamente deben reconocer la pluralidad cultural en la que nuestras sociedades se construyen, solo de esta manera se puede garantizar el verdadero acceso a los mencionados derechos, de lo contrario seguirán existiendo en la formalidad del pergamino.

Bajo estas premisas, en el Ecuador la posibilidad de construir un país plurinacional, multiétnico, diverso e incluyente ha sido una de las apuestas desde los movimientos sociales y el movimiento indígena, lo que ha llevado a incorporar debates y propuestas en torno a otras concepciones de construcción de la sociedad que implicaba el reconocimiento de prácticas ancestrales de pueblos y comunidades, asegurando así mayores posibilidades para el cumplimiento de los derechos humanos.

La importancia de fortalecer la promoción y exigibilidad de los DESCA en nuestras sociedades interculturales implica reconocer esa diversidad en la que convivimos en un mismo territorio; el Estado debe garantizar la inclusión social de toda la población, de lo contrario la homogeneidad estatal occidental como diría De Sousa Santos (2008) se convierte en un obstáculo para la plena realización de los mismos, tanto a nivel individual como colectivo.

En este sentido, propuestas como el Estado Plurinacional, Buen Vivir, derechos de la naturaleza, soberanía alimentaria, economía popular y solidaria, entre otras, tienen como fundamento los DESCA, que son aquellos derechos que contemplan el trabajo, la seguridad social, las diversas formas de vida comunitaria y familiar, prácticas culturales, acceso a la vivienda, alimentación, agua, salud, educación, medio ambiente, etc.

Estas propuestas están respaldadas a nivel internacional ya que los países que han firmado y ratificado el PIDESC, entre ellos Ecuador ${ }^{2}$, se comprometen a garantizar el derecho de toda persona a un nivel de vida adecuado para sí y su

1 Según Houtart (2011) para entender el concepto del Buen Vivir es necesario acudir a los propios actores: "según Luis Macas, expresidente de la CONAIE (Confederación de Nacionalidades Indígenas del Ecuador), habla del espacio comunitario, en donde existe reciprocidad, convivencia con la naturaleza, responsabilidad social, consenso, es decir el "Buen Vivir" (Houtart, 2011). Humberto Cholango, expresidente del mismo organismo en 2011, define el Sumak Kawsay como "un nuevo modelo de vida".

Lo expresado en la Constitución ecuatoriana si bien refleja estos aspectos a nivel estructural, no se vio reflejado en las posteriores leyes y planes que favorecieron un modelo extractivista: "Plan Nacional del Buen Vivir 2013-2017, Objetivo 11: Asegurar la soberanía y eficiencia de los sectores estratégicos para la transformación industrial y tecnológica.» Política 11.2: Industrializar la actividad minera como eje de la transformación de la matriz productiva, en el marco de la gestión estratégica, sostenible, eficiente, soberana, socialmente justa y ambientalmente sustentable". En la práctica esta contradicción llevó a la confrontación entre sectores sociales, campesinos-indígenas y el Estado que tenían perspectivas distintas en torno a la concreción del Buen Vivir.

2 El Estado Ecuatoriano firma el PIDESC el 29 de septiembre de 1967 y lo ratifica el 6 de marzo de 1969, luego de su aprobación en el Registro Oficial Nro. 101 del 24 de enero de 1969. 
familia; alimentación, vestido y vivienda, y a una mejora continua de las condiciones de existencia, para lo cual es necesario políticas que conlleven al cumplimiento de estos derechos. Ecuador atraviesa en la actualidad una contradicción entre las políticas económicas y el cumplimiento de la Constitución y Tratados internacionales relacionados con los DESCA, entre ellos la soberanía alimentaria.

\section{La soberanía alimentaria como parte del Buen Vivir en nuestros pueblos}

Desde la mirada del Buen Vivir se busca la armonía y equilibrio entre seres humanos y naturaleza, esto contempla también la soberanía alimentaria, que a través de la producción de alimentos sanos y culturalmente adecuados para el consumo de los pueblos y naciones, rescata y promueve las tradiciones y conocimientos ancestrales en los métodos de producción y alimentación, incentiva la producción agroecológica y diversificada, cuida las semillas naturales para las futuras siembras.

Uno de los aspectos importantes en la soberanía alimentaria es la consecución de una alimentación adecuada y aceptable culturalmente, así como accesible y con la suficiente disponibilidad, de esta manera se cumple con el derecho a la alimentación ${ }^{3}$, según lo establece la Observación General 12 del PIDESC (Comité de Derechos Económicos, Sociales y Culturales, 1999).

Como se puede ver, la soberanía alimentaria difiere de la propuesta desarrollista de la seguridad alimentaria que en sus máximas promueve la disponibilidad, el acceso, la estabilidad y la utilización de alimentos más no su aceptabilidad y adecuabilidad cultural, limitándose de esta manera a cumplir con los intereses del mercado mundial de alimentos. Por el contrario la soberanía alimentaria ${ }^{4}$ centra su atención en la autonomía y autodeterminación de los pueblos y comunidades, priorizando la producción de alimentos para el consumo familiar y comunitario (La Vía Campesina, 2003). Producción que mayoritariamente es provista por la agricultura familiar campesina (AFC). Según la FAO en 2014 el 70\% de alimentos a nivel mundial es producido por la $\mathrm{AFC}^{5}$.

La actual Constitución del Ecuador, vigente desde 2008, como parte de los derechos del Buen Vivir incorpora el derecho a la alimentación en el Artículo 13 señalando que "toda persona y colectividad tiene derecho al acceso seguro y permanente a alimentos sanos, suficientes y nutritivos, preferentemente estos alimentos serán producidos a nivel local y en correspondencia con sus diversas identidades y tradiciones culturales". Así mismo habla sobre la soberanía alimentaria en sus Artículos 281 y 282 definiéndola como un objetivo estratégico frente al cual el Estado debe garantizar que las personas, comunidades, pueblos y nacionalidades cuenten

3 El derecho a la alimentación está claramente establecido en la Observación General 12 del PIDESC. Además se detalla su implementación en las Directrices Voluntarias del Derecho a la Alimentación aprobadas por la FAO en 2004.

4 El concepto de soberanía alimentaria fue acuñado por primera vez en 1996 en Roma por Vía Campesina, que aglutina al movimiento campesino a nivel mundial, en el contexto de la Cumbre Mundial de la Alimentación de la Organización para la Alimentación y la Agricultura (FAO).

5 En 2014 por tratarse del Año de la Agricultura Familiar Campesina, FAO hace una actualización de la contribución de la AFC en la alimentación del mundo, a posterior no se encuentra nueva información a nivel global solo en el caso de ciertos países. 
autosuficientemente con alimentos sanos y culturalmente apropiados de forma permanente, así mismo el Estado tendrá la facultad para normar el uso y acceso a la tierra bajo principios sociales y ambientales; y regulará el uso, gestión de la tierra, agua y sus fuentes. De esta manera, la soberanía alimentaria va de la mano con el derecho a la alimentación en la construcción del Buen Vivir.

\section{a. Una legislación forjada en las luchas indígenas y sociales}

Las resistencias populares e indígenas al neoliberalismo durante los noventa gestaron nuevos actores sociales quienes se abanderaron de la lucha contra las políticas neoliberales y sus consecuencias para los diversos sectores, tanto en el campo como en la ciudad. Estas luchas traspasaron incluso fronteras nacionales, construyéndose resistencias regionales, cruzadas por un sentimiento antiimperialista y de antiglobalización capitalista.

En el Ecuador el movimiento indígena liderado por la Confederación de Nacionalidades Indígenas del Ecuador (CONAIE) en los noventa realiza el primer gran levantamiento indígena, conocido como el Levantamiento del Inti Raymi, en rechazo a los 500 años de colonización que les han significado exclusión de la sociedad construida desde una mirada occidental, la cual luego de los procesos de independencia tampoco promovieron una sociedad incluyente. A esta protesta anticolonial se juntan las demandas de otros sectores sociales afectados por las políticas privatizadoras del neoliberalismo, de esta manera es el movimiento indígena en los noventa quien se convierte en el referente de lucha y resistencia en Ecuador.

En este contexto, las luchas del campo y la ciudad confluyen en espacios de debate, organización y acción, luchas contra el ALCA (Área de Libre Comercio de las Américas), contra la guerra, contra las privatizaciones, contra la flexibilización laboral, contra las bases militares de Estados Unidos (en el caso de Ecuador en Manta) y contra la globalización capitalista, se convierten en los pilares de resistencia al modelo neoliberal y a las políticas del FMI (Fondo Monetario Internacional) y Banco Mundial que intentan imponerse en la región.

En este periodo, un avance de los procesos de resistencia es haber pasado de la protesta a la propuesta, así la propuesta de realizar una Asamblea Plurinacional Constituyente (CONAIE, 2007) es uno de los acuerdos de los colectivos sociales y del movimiento indígena, ya que es la posibilidad de construir espacios de real participación e inclusión a sectores que toda la vida han estado fuera de los procesos de constitución y estructuración del país.

Esta propuesta de Asamblea Constituyente plantea reformular las estructuras de la sociedad ecuatoriana, que hasta en ese entonces había representado y favorecido a los intereses de las oligarquías y de los sectores dominantes del país, manteniéndose de esta manera una sociedad colonialista. Luego de casi dos décadas de resistencia e incidencia en las calles y en el Estado se logra construir dicha Asamblea con la participación de los diversos sectores, así nace la actual Constitución ecuatoriana con una ampliación de derechos para las minorías, pero también con nuevos fundamentos del tipo de sociedad que se persigue, manteniendo en el horizonte la concreción del Buen Vivir. La actual Constitución reconoce a Ecuador como un Estado Plurinacional, recogiendo así la propuesta de la CONAIE de reconocer a los 
pueblos y nacionalidades que conviven en el territorio ecuatoriano.

b. Sin soberanía del cuerpo no puedo haber soberanía alimentaria

En estos debates, también se encuentran las propuestas de las mujeres, que plantean una mirada más amplia que no reduzca sus demandas a la ampliación de derechos sexuales y reproductivos o a la lucha contra la violencia. Se miran entonces como sujetas políticas que buscan espacios propios de debate, participación desde un accionar propositivo.

El modelo neoliberal también causa grandes efectos en las condiciones de vida de las mujeres: desempleo ${ }^{6}$, precarización laboral, disminución de políticas sociales ${ }^{7}$, aumento de la carga de trabajo, violencia, etc. La crisis económica se profundiza y son las mujeres las que se ven emplazadas a sostener de diferentes maneras sus núcleos familiares y comunitarios, a sostener el diario vivir.

En estas condiciones las mujeres crean diferentes formas de resistencia al neoliberalismo y sus efectos, alternativas que no solo cuestionan las políticas, sino que generan y fortalecen otros relacionamientos sociales y culturales basados en prácticas comunitarias, colectivas, tanto en el campo como en la ciudad. Alternativas que entrecruzan las dimensiones políticas (participación, democracia), económicas (iniciativas productivas y de finanzas populares), culturales (vida comunitaria, saberes ancestrales, solidaridad, reciprocidad), alimentarias (soberanía alimentaria, producción sana y limpia, cuidado de las semillas), ambientales (cuidado de la naturaleza, preservación de los recursos para las futuras generaciones) y sexuales (soberanía del cuerpo, vida sin violencias).

Son estas mujeres confrontando al neoliberalismo desde propuestas concretas, las que plantean en la Asamblea Constituyente una voz propia, no solo para decidir sobre los "temas de mujeres" sino para decidir en qué tipo de sociedad quieren vivir. En medio de estos debates aparece la consigna "sin soberanía del cuerpo no hay soberanía alimentaria", una frase que en el fondo encierra una crítica al sistema patriarcal, en tanto que para conseguir una sociedad del Buen Vivir es necesario también desmontar las estructuras patriarcales, que oprimen a más del $50 \%$ de la población del país. Estructuras patriarcales que se han consolidado en base a la violencia y a la invisibilización del trabajo de las mujeres tanto a nivel social, político, económico, cultural, ambiental.

Así todos los componentes que constituyen el Buen Vivir, incluido la soberanía alimentaria, deben tomar en cuenta las críticas al patriarcado y al colonialismo, para empezar a construir efectivamente otra sociedad.

6 Según el Instituto Nacional de Estadísticas y Censos (INEC), la tasa del desempleo en el Ecuador en los noventa aumentó a alrededor del $15 \%$, en el caso de las mujeres fluctuó entre el 13 y el $20 \%$ alcanzado en 1999 (Sistema de Indicadores Sociales del Ecuador [SIISE], 2006).

7 Mientras en los ochenta la autorregulación del mercado trajo consigo reducción de políticas sociales que permitieron en parte compensar los desequilibrios ocasionados en el ámbito reproductivo, el neoliberalismo puso en primer plano los intereses privados, minimizando el papel del Estado y reduciendo las políticas sociales consideradas como gasto que no aporta a la reproducción del capital y puede ser asumido por los hogares, mayoritariamente por mujeres, niños/as y personas de la tercera edad. 


\section{A la larga noche neoliberal le sucedió un sombrío amanecer extractivista}

Desde el año 1997 al 2003 se da un proceso de fuerte crisis del modelo neoliberal e institucional en Ecuador, tiempo en el cual se dan tres caídas de gobiernos neoliberales producto de grandes movilizaciones sociales en resistencia al neoliberalismo. La candidatura de Rafael Correa en el 2006 logra recoger el descontento popular de la ciudadanía y los movimientos sociales que confrontaron al neoliberalismo por más de una década. El proyecto de la revolución ciudadana se presentaba como una propuesta renovadora que pondría fin a la "larga y triste noche neoliberal" (Pasa la Voz, 2006), representada por los gobiernos de derecha que implementaron las recetas dictadas por el FMI y el Consenso de Washington.

El respaldo de las organizaciones sociales e indígenas a este nuevo proyecto es condicionado y comprometido al llamamiento de la realización de la Asamblea Constituyente como camino que permita la participación directa de la diversidad de sectores del país, y además viabilice las propuestas gestadas por más de 15 años en las luchas sociales.

Luego de ganadas las elecciones, en su primer mandato, Rafael Correa abre el camino para la conformación de la Asamblea Nacional Constituyente que concluye con la creación de la actual Constitución ecuatoriana. Ésta recoge propuestas que venían de los movimientos sociales como el estado plurinacional, economía social y solidaria, soberanía alimentaria, economía del cuidado, producción libre de transgénicos, derechos de la naturaleza, todos estos dentro de la propuesta de la consecución del Buen Vivir. Sin embargo, quedaron temas pendientes como el derecho al aborto que se decían ser muy radicales y generó mucha controversia.

Esta primera fase se inscribe en un momento de transición para América Latina. Después del año 2000 surgen dos procesos casi al mismo tiempo: el neodesarrollismo y el Socialismo del Siglo XXI (Katz, 2006) principalmente con la radicalización del proyecto bolivariano en Venezuela a partir de 2002, que abre la fase de los denominados "gobiernos progresistas". Éstos colocan por un lado la posibilidad de promover crecientes transformaciones radicales (gobiernos de izquierda), y por otro, alcanzar una etapa capitalista de neodesarrollismo regional que cumpla ciertas etapas y con la madurez de las fuerzas productivas permita las transformaciones sociales (Katz, 2006).

Desde el 2009 el gobierno de Correa estableció políticas basadas en un proceso de reformas capitalistas y modernización del Estado en un intento por impulsar la débil capacidad productiva y dependiente de Ecuador, pero sin dejar de ser un país exportador de materias primas, condicionado en sus relaciones de intercambio por la economía y política internacional, dependiente de los productos industrializados del norte global, a la vez que promovía un discurso antiimperialista estadounidense que fortalecía el discurso antineoliberal.

Los factores económicos permitieron que el país avance en ese proceso: altos precios del petróleo, remesas de migrantes que a pesar de la crisis en Europa mantienen el rubro de ingresos monetarios en Ecuador, incremento y ampliación de impuestos, pero la fuente principal y constante será la extracción de recursos naturales base de la nueva matriz productiva y energética. 
El gobierno de Correa promovió la rentabilidad para salir del neoliberalismo, lo que ha significado una explotación exacerbada de los recursos naturales como base para el nuevo desarrollo. Tal como lo explica Pedro Montes, la búsqueda de la maximización de la tasa de rentabilidad del capital enfrentada a los cuidados requeridos con la naturaleza y la preservación del equilibrio ecológico. Así, el extractivismo a gran escala y el agronegocio tomaron fuerza en la política gubernamental promoviendo un cambio de la matriz productiva y energética con base en los megaproyectos mineros, hidroeléctricos, petroleros, monocultivos. Esto tomó forma concreta en el Plan Nacional del Buen Vivir 2009-2013, la Agenda para la Transformación Productiva 2010 basada en el Plan de Desarrollo 2007-2010 y Plan Nacional para el Buen Vivir 2013-2017, así como la Ley de Minería e Hidrocarburos de 2009 (la cual coloca a la minería como sector estratégico nacional), la Ley de Código de la Producción, el Plan Tierras de2009 (que promovía una redistribución de las tierras del Estado más no de los grandes terratenientes), la Ley de Tierras de 2016 (que no controla el latifundio y por ende el acaparamiento de tierras), y la Ley de Recursos Hídricos de 2014 (que deja el poder de decisión del uso y gestión en manos exclusivas del Estado como autoridad única, sin la participación de los sectores sociales).

Evidentemente, el gobierno de Correa fue cediendo su conducción hacia los sectores monopólico-productivos, frases como "mendigos sentados en un saco de oro" daban cuenta del viraje hacia una clara política extractivista (Martinez Alier, 2012). En este contexto, el Ecuador asiste a una nueva configuración de grupos de clase, que atraviesan contradicciones entre conservar la ganancia y el poder obtenido bajo el modelo neoliberal y grupos que, partiendo de esa anterior forma de acumulación, se desprenden y buscan otras formas no neoliberales para emerger. Con el ascenso del gobierno de Lenin Moreno (del mismo movimiento de Rafael Correa) se definen más claramente los grupos económicos de poder anclados en el nuevo gobierno, una élite empresarial que regresa con fuerza y legitimidad a "salvar la crisis" de la década ganada ${ }^{8}$, profundizando las políticas neoliberales y extractivistas.

En estos últimos años, la crisis económica mundial junto a la crisis de precios del petróleo (primer rubro de ingresos para Ecuador) empiezan a tener sus consecuencias en Ecuador. Esto hace que las políticas del Estado vuelvan a mirarse desde el neoliberalismo (privatizaciones, flexibilización laboral, endeudamiento externo) lo que se profundiza con el gobierno de Lenin Moreno, avanzando aceleradamente con la extracción minera, petrolera y el agronegocio. Esto solo demuestra que no se acaba de salir de la noche neoliberal pero tampoco el amanecer es totalmente neodesarrollista, por el contrario, en los últimos años se retorna al neoliberalismo abiertamente, anulando de esta manera el Buen Vivir como propuesta alternativa de vida, aunque fuere utilizado desde los gobiernos progresistas para la institucionalización de ciertas demandas sociales (Gudynas, 2014). En este campo los sectores sociales siguen resistiendo amparados en la Constitución ecuatoriana que aún mantiene su horizonte del Buen Vivir, aún con la permanente amenaza de ser reformada, resistencias que han permitido en parte frenar la avanzada extractivista pero con mucha debilidad.

8 Hace referencia a cómo el gobierno de Correa denomia todo su período presidencial. 
El actual gobierno de Lenin Moreno, en inicio realizó ciertos cambios en la política social, que daban indicios de conciliación con los sectores sociales y el movimiento indígena, comprometiéndose a la amnistía de los dirigentes judicializados así como limitar la injerencia en otras funciones del Estado. Sin embargo, sus políticas posteriores han llevado a un regreso legitimado y con fuerza del neoliberalismo a través de los acuerdos con el FMI que comprometen derechos laborales y sociales, a su vez un crecimiento acelerado de la deuda externa para fortalecer la empresa privada que "promete" creación de fuentes de empleo, y la continuidad de los proyectos extractivistas (Yasuní y minería). Con su alineación a Estados Unidos, China, y países de la región con gobiernos de derecha ha dejado anulada la posibilidad de alianzas alternativas y pone en riesgo los avances en torno a soberanía alimentaria con la implementación de sus políticas extractivistas, el pasado jueves 18 de julio de 2019 dio inicio a la fase de explotación de cobre en la cordillera Cóndor Mirador con lo cual el gobierno anuncia triunfante que Ecuador empieza su época de megaminería.

\section{La situación de la soberanía alimentaria en el Ecuador}

La soberanía alimentaria es el derecho de los pueblos a definir sus propias políticas de agricultura y alimentación, a proteger y regular su producción y el comercio agrícola interior para lograr sus objetivos de desarrollo sostenible, a decidir en qué medida quieren ser autónomos y a limitar el dumping de productos en sus mercados (Vía Campesina).

El ejercicio pleno de la soberanía alimentaria implica contar con la disponibilidad de tierras, semillas, agua, créditos, espacios de comercialización. Para cumplir con lo establecido en la Constitución en el tema de soberanía alimentaria, se aprobó en Febrero de 2009 la Ley Orgánica del Régimen de Soberanía Alimentaria (LORSA). Sus ejes temáticos son: acceso al agua y a la tierra y uso de ellas; protección de la agrobiodiversidad; investigación, asistencia técnica y diálogo de saberes; fomento de la producción; acceso al capital e incentivos; comercialización y abastecimiento agroalimentario; sanidad e inocuidad alimentaria; consumo y nutrición, y, participación social para la soberanía alimentaria.

A continuación se analizan los alcances que tuvieron dichas leyes y su repercusión en la población:

1) La Secretaría Nacional de Planificación y Desarrollo (SENPLADES) formuló el Plan Nacional del Buen Vivir 2009-2013. Entre sus objetivos se planteó superar las desigualdades en salud, educación, alimentación; asegurar una alimentación, sana, nutritiva, natural, con productos del medio; democratizar los medios de producción; y reducir la dependencia externa alimentaria y energética.

2) Sin embargo, un estudio realizado por el Instituto de Estudios Ecuatorianos (IEE) en $2010^{\circ}$ evidencia que el gobierno de Correa ha invertido menos en agricultura que los gobiernos anteriores, y que los proyectos no toman en cuenta la calidad, ni necesidad de los productores. De esta manera Ecuador sigue atado al monocultivo; los campesinos y las mujeres no son considerados sujetos productivos, sino de

9 El estudio se basa a la información del último Censo Agrario realizado en el año 2000. No se cuenta con información más actualizada porque oficialmente no se ha realizado el nuevo Censo Agrario que debía realizarse en 2010 (aún no hay una proyección de cuándo se lo realizará). 
asistencia, y, lo más grave, es que la inversión en agricultura sigue beneficiando a medianos y grandes productores en detrimento de la agricultura familiar campesina. Para Herrera (2017):

El "modelo" de agricultura en el Ecuador, en sus rasgos generales, no ha cambiado: por un lado, existe un polo primario-agroexportador que se sostiene sobre el control de los recursos productivos más importantes (tierra, agua, tecnología) y la sobre explotación laboral (trabajadores sin mayores avances en el reconocimiento de sus derechos laborales); un importante sector, de pequeños y medianos productores al centro; y en el otro extremo, una enorme proporción de pequeños agricultores que basan su "economía de subsistencia" en las actividades familiares, acusados de ser ineficientes o improductivos.

Uno de los problemas más graves en Ecuador es el acaparamiento de tierras. Según el Censo Agropecuario de 2000 "las propiedades menores a una hectárea que representan una cuarta parte del total de las unidades productivas, apenas tienen el $1 \%$ de la tierra, mientras que las propiedades mayores a cien hectáreas, que representan apenas $2 \%$ del total, poseen el $43 \%$ de las tierras cultivables" (FIAN Ecuador, 2010) ${ }^{10}$.

En 2009, la Subsecretaría de Tierras lanzó el conocido Plan tierras y territorios, cuyo propósito era la redistribución de 2,5 millones de hectáreas de tierras estatales en cuatro años. El estudio de FIAN Ecuador (2010) revela que el plan no ha garantizado la tenencia de la tierra de familias posesionarias; por el contrario, provocó falsas expectativas con personas vinculadas a la especulación de la tierra y generó conflictos en las haciendas; división, violencia y hasta asesinatos. Hasta 2012 el Coeficiente de Gini en lo referente al acceso a tierras llegó a 0,78. En 2014 la SENPLADES (en la publicación de la Estrategia para la Igualdad y la Erradicación de la Pobreza) confirma que Ecuador mantiene un modelo de desarrollo agropecuario que excluye al campesino y acapara las tierras cultivables: la pequeña y mediana agricultura representan el $84,5 \%$ de las Unidades Productivas Agrícolas (UPAs) y controlan el $20 \%$ de la superficie de tierra, mientras que la agricultura a gran escala representa el $15 \%$ de las UPAs y concentra el $80 \%$ del suelo cultivable.

Si bien la Constitución junto con la LORSA son los instrumentos jurídicos más importantes para el cumplimiento de la soberanía alimentaria, existen leyes que están vigentes y se contraponen a los mandatos de la misma, pues favorecen la acumulación capitalista en el agro, no fortalecen la propiedad comunal sobre la tierra, y orientan la capacitación en gerencia empresarial, agroindustria y agroexportación. Es el caso de la Ley de Desarrollo Agrario de 2010, que derogó la Ley de Reforma Agraria, eliminó las vías de afectación a la concentración de la propiedad, tales como extinción y reversión de dominio, y eliminó toda forma de regulación y limitación a la propiedad agraria fomentando el mercado de tierras, incluidas las tierras comunitarias, entre otras disposiciones.

Para conocer si efectivamente el Ecuador se encamina hacia la soberanía alimentaria, basta analizar las cifras de inversión en agricultura. El estudio realizado por el IEE en 2012 muestra que, si bien ha habido un incremento de la inversión pública en

10 FoodFirst Information and Action Network: https://www.fian.org/es/. 
agricultura, esta no produjo una reorientación de los beneficiarios de la actual estructura de desarrollo agropecuario. En relación a la producción de alimentos a nivel local y acordes a la diversidad cultural, en la realidad ecuatoriana se importa el $94 \%$ del trigo, el $86 \%$ de la avena, el $73 \%$ de la lenteja, el $70 \%$ de almidones, y el $62 \%$ de la cebada.

3) Otro hecho preocupante en la efectivización de la soberanía alimentaria en Ecuador son las declaraciones del entonces presidente Rafael Correa, al plantear en 2012 que "las semillas genéticamente modificadas pueden cuadruplicar la producción y sacar de la miseria a los sectores más deprimidos". Este pronunciamiento contradice a lo señalado en la Carta Constitucional en su Artículo 401 que afirma que "Ecuador es libre de cultivos y semillas transgénicas", lo que se ratifica en el Artículo 26 de la LORSA donde se "declara al Ecuador libre de cultivos y semillas transgénicas. (...) Se prohíbe la aplicación de biotecnologías riesgosas o experimentales".

A estas declaraciones les subyace un intento por reformar la norma constitucional por considerar "un error" mantener estos principios de no a los transgénicos, lo cual se concretó el 5 de Mayo de 2017 con la aprobación de la ley de semillas y biodiversidad por parte de Rafael Correa, días antes de terminar su mandato. Con esta reforma se pone en peligro la soberanía alimentaria en el país, ya que a futuro se comenzará a producir alimentos con semillas transgénicas, todos bajo una cobertura de "experimentos", perjudicando la producción y consumo de alimentos apropiados culturalmente, lo que significa también afectaciones en la salud y las formas de vida. Entre las principales reacciones ante estas declaraciones se registra la de Vía Campesina (2012) que recordó al entonces presidente Correa su anterior compromiso por fortalecer la agricultura familiar campesina, nada de esto frenó esta Ley. Actualmente, el Decreto emitido a última hora por Correa está detenido debido a demandas de inconstitucionalidad planteadas por diversos sectores sociales, sin embargo, ya se han registrado casos de semillas transgénicas en cultivos de soja en la costa ecuatoriana, hecho que fue denunciado por los campesinos y "obligó al Ministerio de Agricultura y Ganadería (MAG) a tomar las medidas necesarias para erradicar los cultivos y monitorear que no ingresen semillas transgénicas al país con fines productivos, y así cumplir con el mandato popular de un Ecuador libre de transgénicos" (Artacker y Daza, 2019).

Dentro de las políticas estatales dispuestas en la LORSA para el cumplimiento de la soberanía alimentaria están la creación de la Ley de aguas, la Ley de tierras, la Ley minera, la Ley de biodiversidad y semillas. Todas estas han significado una confrontación directa entre el gobierno y las organizaciones sociales e indígena que exigían coherencia con lo aprobado en la Constitución, donde se exige el respeto al derecho a la consulta previa e informada de la población. Por esta razón, muchos dirigentes fueron acusados de terrorismo, sedición y sabotaje, con el actual Código Orgánico Integral Penal (vigente desde 2014): las figuras jurídicas han cambiado más no la persecución, represión, judicialización y condena a dirigentes sociales, ya existen varios casos de encarcelamiento ${ }^{11}$. De estos casos se han realizado

11 Javier Ramírez (presidente comunidad Junín-Intag, Carlos Pérez Guartambel (dirigente Ecuarunari), Pepe Acacho (dirigente Shuar CONAIE [Confederación de Nacionalidades Indígenas 
varios informes de derechos humanos a nivel nacional e internacional, la última investigación realizada por Calapaqui (2017), constató que durante el gobierno de Rafael Correa se judicializó a alrededor de 700 dirigentes sociales hasta $2017^{12}$.

Por otro lado, durante los últimos años se han creado diversos programas para garantizar el acceso de alimentos a las poblaciones vulnerables. En la actualidad se cuenta con el Programa Acción Nutrición (Ministerio Coordinador de Desarrollo Social, 2013), que promueve una política nacional de seguridad alimentaria y nutricional, basada en un trabajo intersectorial a nivel estatal con la participación de la sociedad, y busca la equidad en el acceso a la alimentación adecuada, descentralizando las acciones, presupuesto y gestión en los actores gubernamentales, dejando de lado la soberanía alimentaria. Dentro de las debilidades de estos programas se evidencia un constante cambio al no cumplir con los objetivos propuestos, asimismo los cambios de estructuras y entidades responsables de dar seguimiento y poner en ejecución dichos programas, hace que se vuelvan políticas asistencialistas y de corto plazo; con resultados mínimos de acuerdo a lo propuesto en los Objetivos del Milenio ${ }^{13}$ y en el Plan de desarrollo del Buen Vivir.

\section{Las incompatibilidades entre el extractivismo y la soberanía alimentaria}

El extractivismo es la extracción de recursos naturales en grandes volúmenes o de alta intensidad de recursos naturales, orientados principalmente a la exportación en calidad de materias primas que serán llevadas para su procesamiento en el exterior (Gudynas, 2013). A partir de ello podemos decir que no toda actividad que utilice recursos naturales de por sí es una actividad extractivista. Así la agricultura familiar campesina, que provee aproximadamente el $70 \%$ de los alimentos a nivel mundial, utiliza esos recursos (agua, tierra, semillas, etc.) pero siempre pensando en una lógica de recomposición de los mismos para futuras siembras y cosechas.

En la actualidad, los grandes capitales transnacionales han puesto en la mira a los recursos naturales, la propuesta del neodesarrollismo circula en la región y el capitalismo gira en torno a políticas extractivistas a gran escala, que implican un uso intensivo de maquinaria, como ocurre con la megaminería a cielo abierto, la extracción petrolera a gran profundidad o los monocultivos, donde las cantidades de tierra o agua a remover sobrepasan los millones de toneladas, en el caso de la minería o el petróleo y a ocupar miles de hectáreas en el caso de los monocultivos como el caso de la soja en el Cono Sur.

Toda esta propuesta extractivista implica un uso intensivo de insumos químicos (como cianuro o mercurio en la minería, aditivos en los pozos petroleros, o agrotóxicos en la agricultura). Así mismo, el consumo de ingentes cantidades de energía, lo que implica una fuerte inversión en las hidroeléctricas y que conlleva fuertes impactos ambientales tanto en el aire como en la tierra y las fuentes de agua, que luego irán

del Ecuador]) y comuneros de Tundayme-Amazonía sur, entre otros.

$12 \mathrm{Al}$ iniciar el actual gobierno, la CONAIE presentó un pedido de Amnistía Internacional e indulto para parte de los enjuiciados en el gobierno anterior (Plan V, 2017), lo cual ha sido aceptado en su mayoría, algunos aún se encuentran en trámite para la amnistía en la Asamblea Nacional.

13 En el Mapa del Hambre 2015 de FAO, en la evaluación de los Objetivos del Milenio se dice que Ecuador no cumplió con la meta propuesta. 
para el consumo humano de las poblaciones aledañas.

Esta propuesta de desarrollo que trae consigo el avance del capitalismo transnacional y la idea de a mayor consumo mayor progreso, trae también graves consecuencias producto del extractivismo, basta regresar a ver los impactos ambientales, sociales y culturales en zonas como Yanacocha en Perú, Carajás en Brasil, Cóndor Mirador en Ecuador, donde lo único que ha quedado es la precarización de los pueblos y comunidades con pérdidas irreparables en sus territorios.

Entre los impactos sociales, ambientales, económicos, políticos e incluso culturales, están la contaminación, la pérdida de prácticas productivas locales, conflictos ciudadanos, expulsión de pueblos y comunidades indígenas de sus territorios, como en el caso de Ecuador, en la cordillera Cóndor Mirador (amazonia sur) y en Intag (sierra norte). Todos estos impactos significan una violación a los derechos humanos de los sectores donde se implementan estos proyectos, pues se prioriza los recursos naturales para las grandes transnacionales privando de los recursos básicos como agua, tierra y alimentos sanos a las poblaciones.

Sin embargo, no podemos dejar de observar que este mercado de recursos naturales depende de los mercados internacionales, ya que las materias primas extraídas desde América Latina en su gran mayoría son procesadas en otros continentes, así, sin demanda global, buena parte de las extracciones latinoamericanas no existirían, pero se desarrollan en un sitio específico (sea zona minera, un pozo de petróleo o un predio agrícola) y por lo tanto, los impactos son siempre locales, afectan a las comunidades locales.

Como vimos en un inicio, la posibilidad de fomentar la soberanía alimentaria implica el acceso a agua, tierra y semillas para la producción de alimentos sanos, así como el respeto a decidir sobre las formas de producción y el tipo de alimentos a consumir de acuerdo a sus costumbres y culturas. El extractivismo por el contrario busca la explotación de los recursos naturales para el usufructo de los capitales transnacionales, lo que hace que éste se vuelva un obstáculo para la soberanía alimentaria y por ende para el Buen Vivir.

\section{Situación de las mujeres ecuatorianas en relación a la soberanía alimentaria}

Las mujeres son un factor clave en el sostenimiento de la soberanía alimentaria, dado que son quienes, como producto de la división sexual del trabajo, han asumido los trabajos de cuidados, entre ellos la alimentación, que va desde la producción de los alimentos hasta su consumo. Son las mujeres las guardianas de la semilla, las transmisoras de saberes culinarios y curativos, las cuidadoras de la naturaleza, las protectoras de sus territorios, pues son ellas quienes son responsables de la sostenibilidad de la vida de sus familias y de su comunidad. Son ellas quienes han construido alternativas frente a las crisis económicas.

El neoliberalismo promovió una reestructuración del trabajo productivo ${ }^{14}$ remunerado

14 Desde el año 2008, se reconoce como trabajo productivo a toda forma actividad que genera un valor, realizado por las mujeres dentro y fuera del hogar, y por ello, se pasan a reconocer las categorías de remunerado y no remunerado, como trabajos que sostienen la vida, no solo de las familias ecuatorianas sino que están incorporados en el aparato productivo, en la economía de la 
y no remunerado. El empobrecimiento fruto de la crisis colocó otras responsabilidades sobre las mujeres como la intensificación del trabajo doméstico al recortarse el presupuesto estatal para el sector social, así como la disminución de ingresos familiares para pagar estos servicios por fuera del hogar, así mismo se ven en la necesidad de buscar otras fuentes de ingresos de esta manera se amplía el trabajo informal a través de microempresas, auto-empleo, trabajo no pagado y trabajo de subsistencia (Vasconez en Prieto, 2005); en otros casos el trabajo remunerado se intensificó lo que implicó condiciones laborales más precarias y con el constante riesgo de despidos.

Se produce la feminización de todos los aspectos de la vida productiva del campo y la ciudad, las mujeres se incorporan en el trabajo asalariado en el campo agrícola, de comercialización, distribución y consumo, y a su vez continúan siendo las responsables de la economía del cuidado.

En el trabajo remunerado, la mayoría de las mujeres acceden a trabajos precarios, de auto-subsistencia, sin responsabilidad del Estado, sin acceso a derechos laborales, generando un ingreso básico con un altísimo y desproporcionado incremento de horas de trabajo acumulado, para lograr sostener el acceso al empleo, en comparación a los hombres.

El trabajo no remunerado, también sufre una reestructuración. Si bien sigue en manos mayoritariamente de las mujeres, este se vuelve extensivo a otras mujeres, por decir, empleadas domésticas, hijas, abuelas. La esfera del cuidado se sostiene de esta forma, para lograr el ingreso de las mujeres al trabajo remunerado. De acuerdo a la Encuesta del Uso del Tiempo en Ecuador (INEC, 2012), las mujeres trabajan remuneradamente $46: 15$ horas a la semana, mientras que los hombres lo hacen un promedio de 51:36 horas a la semana. Esto es 5:20 horas los hombres más que las mujeres, en área urbana llega hasta 6:50 horas. Mientras que en el trabajo no remunerado las mujeres designan 24:06 horas semanales frente a las 6:00 horas que le dedican los hombres. Lo que significa una diferencia de 18 horas. De esta manera la carga global del trabajo recae en las mujeres.

En medio de la crisis, las actividades que crean las mujeres para llevar el alimento a sus hogares, contemplan en el fondo prácticas con rasgos de soberanía alimentaria, demandando al estado el derecho a una alimentación sana y segura.

Estas prácticas fortalecen formas ancestrales de promoción de la producción sana y responsable y de formas colectivas para el sostenimiento del consumo; se incorpora la promoción de experiencias económicas comunitarias que permiten construir redes para el sostenimiento de la vida basada en el alimento como el espacio para compartir y asegurar alimentación sana, no para la ganancia ni la acumulación capitalista.

Aquello que se estaba forjando en los espacios sociales, muchos promovidos por organizaciones de mujeres diversas, campesinas, indígenas, afroecuatorianas, mestizas, montubias, y los ensayos de vinculación entre las luchas étnicas, de género y de resistencia a un modelo de desarrollo, lograron incentivar el derecho a la alimentación junto con la soberanía alimentaria.

Posterior a 2008, a pesar de estos procesos de democratización tan importantes, se sociedad ecuatoriana. 
abre la tensión entre la ejecución y las normas constitucionales. La disputa política se cierne entre el Estado y los procesos de resistencia social. Allí continúa y está la tensión fundamental. El Estado busca cierta inclusión y ejecución de derechos, sin afectar la gran propiedad, ni a los grupos de poder, y las luchas de resistencia, mantienen la exigencia del cumplimiento pleno, no solo de la normativa constitucional, sino de la democracia amplia y plural como elemento que debe componer la relación entre el Estado y la sociedad.

En la norma constitucional las mujeres logran incorporar sus demandas específicas como acceso al crédito, cuidado de las semillas, reconocimiento del trabajo reproductivo comunitario. Sin embargo, en la práctica no se ha logrado una mayor incidencia en las mujeres quienes aún siguen con dificultades para acceder a créditos, limitada participación en política pública relativa al acceso a tierra, aguas, semillas, a pesar de ser las principales actoras en las luchas por la defensa de sus territorios, por el agua, la tierra, las semillas y contra los proyectos megaextractivistas.

Transversalizar el enfoque de género en la soberanía alimentaria implica cuestionar la disparidad de poder entre el acceso a la decisión y al trabajo, los ciclos de la producción, los círculos productivos, de comercialización, de distribución, sean compartidos entre hombres y mujeres de manera justa. Es necesario que se reconozca y redistribuya el trabajo de las mujeres en las esferas de cuidado y la corresponsabilidad en la producción y provisión de alimentos para la reproducción de la vida.

\section{La soberanía alimentaria, una deuda pendiente del Estado ecuatoriano en la construcción del Buen Vivir y el respeto a los DESCA.}

De lo dicho a lo largo del trabajo, se ve que un modelo de desarrollo basado en el extractivismo es totalmente contrario a la construcción de la soberanía alimentaria, y por ende vulnera la garantía, promoción y ejecución de los DESCA.

* En el caso ecuatoriano, el Estado está incumpliendo con su obligación de garantizar y proteger la soberanía alimentaria, frente a actividades de terceros y por las propias actuaciones del mismo como los megaproyectos extractivistas, los cuales no han sido realizados con los parámetros establecidos en la Constitución y en tratados internacionales como el Convenio 169 de la Organización Internacional del Trabajo, donde se establece que: "en caso de proyectos que impliquen un impacto sobre comunidades indígenas, los Estados tienen que realizar la consulta previa con el fin de obtener el consentimiento de los miembros de la comunidad afectada".

Un ejemplo claro es el caso del Proyecto Minero de Kimsacocha en el cual no se ha realizado dicha consulta a los miembros de las comunidades que resultarían afectadas, ni tampoco se ha tomado en cuenta la consulta comunitaria realizada en octubre de 2011 en dos parroquias afectadas directamente (Pérez Guartambel, 2012). Este proyecto afectaría principalmente a las fuentes de agua, provocando una disminución de los humedales existentes en Ecuador. Otro ejemplo, reciente es la comunidad Tundayme en la Cordillera del Cóndor, donde a pesar de la resistencia de sus pobladores amparándose en su derecho a preservar sus territorios ancestrales como parte de los derechos colectivos han sido desalojados violentamente. De acuerdo al catastro minero de enero del 2018, luego del 11 de diciembre (fecha en la 
que el presidente Moreno, se comprometió a no entregar más concesiones) se han entregado cerca de 70.000 nuevas hectáreas mineras principalmente a empresas transnacionales (Asamblea de los Pueblos del Sur, 2018).

* La implementación de programas alimentarios presenta prácticas discriminatorias, derivadas aún de una política clientelar. Su naturaleza asistencialista amenaza la sostenibilidad del acceso a los alimentos de los destinatarios de los programas, y no garantizan la soberanía alimentaria. Adicionalmente, los programas no cumplen con los elementos normativos de la adecuabilidad y aceptabilidad cultural de las ayudas alimentarias. Ni tampoco contemplan el trabajo de cuidados que recae mayoritariamente en las mujeres.

* En Ecuador los gobiernos han mantenido el discurso del Buen Vivir y los derechos de la naturaleza, consagrados en la Constitución y que son perfectamente armónicos con los DESCA, sin embargo, se ha criminalizado la protesta de los movimientos sociales en defensa de dichos derechos humanos, y se ha debilitado o dividido a las organizaciones sociales históricas bajo el argumento de defensa del interés general.

Sin embargo, una propuesta alternativa que promueva el Buen Vivir a través de la soberanía alimentaria, la economía popular y solidaria, los derechos colectivos, los derechos de la naturaleza entre otros, no pasa sólo por la reforma institucional del Estado, pasa por la construcción de procesos colectivos locales, nacionales, regionales e internacionales tanto a nivel de sectores sociales como gubernamentales, reconociendo la diversidad cultural y generando espacios reales de participación y democracia.

* Pensar otro modelo de sociedad no basada en el extractivismo es posible si se reconocen las prácticas de vida comunitarias, desde los pueblos y nacionalidades, desde las mujeres, desde los campesinos/as.

\section{Referencias bibliográficas}

Artacker, T. y Daza, E. (2019). Campesinos vs. Transgénicos: La sentencia de Los Ríos. La Línea de Fuego. Recuperado de: https://lalineadefuego. info/2019/02/05/campesinos-versus-transgenicos-la-sentencia-de-los-rios/

Asamblea de los Pueblos del Sur. (2018). Nuevas concesiones mineras. Asamblea de los Pueblos del Sur. Recuperado de: https://www.facebook.com/ AsambleaPueblosdelSur/?hc_ref=ARSWrVAXB6W83mYCBhbHebx3ospel VOLiCQeS6TjD0Wfx2CZRS3pJUU2X9RPbBZtBhU\&fref=nf\&pnref=story

Calapaqui, T. K. (2017). Criminalización de la Protesta: 2007-2017, las victimas del correismo. Quito, Ecuador: Fundación Dayuma.

Comité de Derechos Económicos, Sociales y Culturales (2012). Observación General 12. El derecho a una alimentación adecuada (Artículo 11). Recuperado de: http://www.acnur.org/fileadmin/scripts/doc.php?file=fileadmin/Documentos/ BDL/2001/1450 
Committee on Economic, Social And Cultural Rights. (1966). International Covenant on Economic, Social and Cultural Rights. Recuperado de: https:// treaties.un.org/Pages/ViewDetails.aspx?src=TREATY\&mtdsg_no=IV$3 \&$ chapter $=4 \&$ clang=_en

CONAIE. (2007). Propuesta de la CONAIE frente a la Asamblea Constituyente. Principios y lineamientos para la nueva constitución del Ecuador. Por un Estado Plurinacional, Unitario, Soberano, Incluyente, Equitativo y Laico. Quito: Ecuador, CONAIE.

De Sousa Santos, B. (2008). Estados Plurinacionales y Constituyente. ALAI. Recuperado de: https://www.alainet.org/es/active/23957

FIAN Ecuador. (2010). Monitoreo de políticas de redistribución de tierra estatal y el Derecho a la alimentación de los posesionarios. Quito, Ecuador: Zonacuario

Gudynas, E. (2014). Buen Vivir: sobre secuestros, domesticaciones, rescates y alternativas, en Atawallpa Oviedo, F. (Comp), Bifurcación del Buen Vivir y el Sumak Kawsay. Quito, Ecuador: Ediciones Sumak.

Gudynas, E. (2013). Extracciones, extractivismos y extrahecciones. Observatorio del Desarrollo, (18).

Herrera, S. (2017). El "paquetazo agrario": Claves para entender la política agraria en el Ecuador. La Línea de Fuego. Recuperado de: https://lalineadefuego. info/2017/08/30/el-paquetazo-agrario-claves-para-entender-la-politicaagraria-en-el-ecuador-por-stalin-herrera/

Houtart, F. (2011). El concepto de sumak kawsai (buen vivir) y su correspondencia con el bien común de la humanidad. ALAl. Recuperado de: https://www. alainet.org/es/active/47004.

INEC (2012). Encuesta del Uso del Tiempo en Ecuador.

Katz, C. (2006). El rediseño de América Latina: ALCA, MERCOSUR y ALBA. Buenos Aires, Argentina: Ediciones Luxemburg.

Martínez Alier, J. (2012). Quimsacocha: "mendigos sentados en un saco de oro". La Línea de Fuego. Recuperado de: https://lalineadefuego.info/2012/10/09/ quimsacocha-mendigos-sentados-en-un-saco-de-oro/

Ministerio Coordinador de Desarrollo Social. (2013). Programa Acción Nutrición. Recuperado de: http://www.desarrollosocial.gob.ec/programa-accionnutricion/

Organización de las Naciones Unidas para la Alimentación y la Agricultura [FAO]. (2005). Directrices Voluntarias del Derecho a la Alimentación. Recuperado de: http://www.fao.org/docrep/009/y7937s/y7937s00.htm

Pasa la Voz. (2006). "Ecuador superará la triste noche neoliberal": Rafael Correa. Recuperado de: https://movimientos.org/es/noalca/integracionpueblos/ 
show_text.php3\%3Fkey\%3D8787

Pérez Guartambel, C. (2012). Agua u oro: Kimsacocha la resistencia por el agua. Universidad Estatal de Cuenca, Ecuador.

Prieto, M. (2005). Mujeres ecuatorianas. Entre las crisis y oportunidades 1990-2004. Quito, Ecuador: Rispergraf.

Plan V. (2017). Conaie: La lucha por la Amnistía. Plan V. Recuperado de: https:// www.planv.com.ec/historias/politica/conaie-la-lucha-la-amnistia

Registro Oficial. (2008). Constitución de la República del Ecuador. Recuperado de: https://www.corteconstitucional.gob.ec/images/contenidos/quienes-somos/ Constitucion_politica.pdf

Sistema de Indicadores Sociales del Ecuador [SIISE]. (2006). Boletín Nro. 8. Recuperado de: http://www.siise.gob.ec/siiseweb/PageWebs/pubsii/ pubsii_0043.pdf

Vía Campesina. (2013). Qué es la SoberaníaAlimentaria. Vía Campesina. Recuperado de: https://viacampesina.org/es/que-es-la-soberania-alimentaria/

Vía Campesina. (2012). Transgénicos: Carta de la Vía Campesina a Rafael Correa, Presidente de Ecuador. Recuperado de: http://www.cloc-viacampesina.net/ es/temas-principales/soberania-alimentaris-y-comercio/1273-transgenicoscarta-de-la-via-campesina-a-rafael-correa-presidente-de-ecuador 